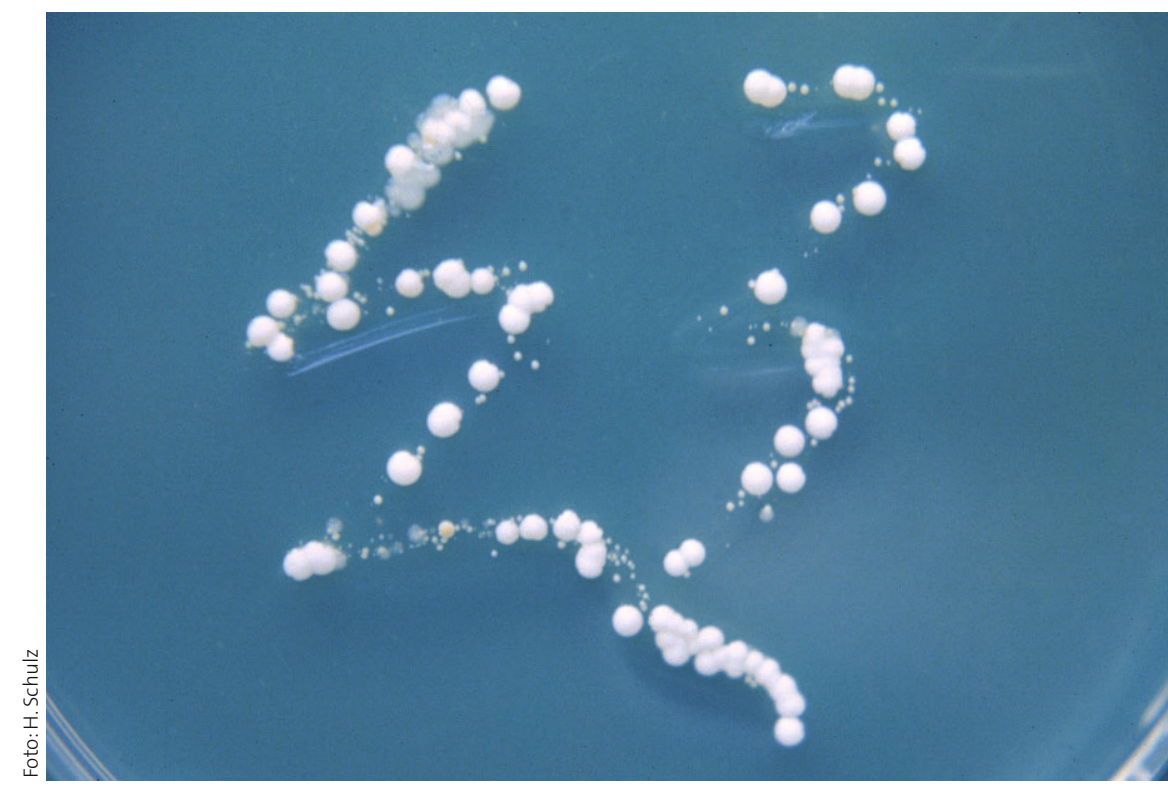

Candida albicans: Nur ein Antimykotikum kann den Erreger eliminieren.

\section{Homöopathie bei Candidiasis?}

Die Homöopathie begreift Candida albicans als Nosode und beschreibt zahlreiche Kuren gegen die Candidiasis. Jetzt wurde untersucht, ob eine klassische homöopathische Behandlung mit einer antimykotischen Therapie mithalten kann.

- Österreichische Gynäkologen randomisierten 150 Frauen mit vulvovaginaler Candidiasis in drei Gruppen. Gruppe A erhielt Itraconazol plus Lactobacilli, Gruppe B erhielt Itraconazol ohne Zusatz und Gruppe C wurde nach den Regeln der klassischen Homöpathie behandelt. Die Therapiedauer betrug zwölf Monate.

Nach sechs Monaten waren die Candidakulturen in 90\% (Gruppe A), 85\% (Gruppe B) und 47\% (Gruppe C) negativ. Nach zwölf Monaten lagen diese Prozentsätze bei 76\%, 78\% und 39\%. Die subjektiven Beschwerden folgten einem ähnlichen Muster: In der homöopathisch behandelten
Gruppe klagten die Patientinnen am meisten über den ausbleibenden Effekt der Behandlung und über anhaltende Beschwerden.

KOMMENTAR: Eine homöopathische Therapie der Candidiasis wird von Homöopathen häufig empfohlen. Die hier gewählte homöopathische Behandlungsform war individualisiert auf die speziellen Charakteristika jeder Patientin. Aus homöpathischer Sicht ist diese Vorgehensweise die wirksamste. Die Daten zeigen jedoch, dass diese Therapie der konventionellen Behandlung mit Itraconazol deutlich unterlegen ist. Ferner zeigen sie, dass man sich die adjuvante Therapie mit vaginalen Lactobacilli sparen kann.

E. ERNST

- A. Witt et al.

Monthly itraconazole versus classic homeopathy for the treatment of recurrent vulvovaginal candidiasis: a randomised trial. BJOG. 116 (2009) 1499-1505

\title{
Achtung:
}

\section{Hier muss der Dummy durch eine Anzeige ersetzt werden !!}

